\title{
CHEMICAL MODIFICATION OF PINE WOOD WITH PROPIONIC ANHYDRIDE: EFFECT ON DECAY RESISTANCE AND SORPTION OF WATER VAPOUR
}

\author{
Antonios N. Papadopoulos \\ The purpose of this paper is to show the effects of level of substitution \\ with a linear chain anhydride (propionic anhydride) on decay resistance \\ and on water vapour sorption of modified Scots pine sapwood. The work \\ described herein has demonstrated that chemically modified Scots pine \\ sapwood with propionic anhydride afforded substantial bioprotection \\ against Coniophora puteana. It required a weight gain of approximately \\ $17 \%$ following reaction to ensure complete protection. The sorption of \\ water vapour of propionic anhydride modified wood was greatly reduced.
}

Keywords: Chemical modification, Propionic anhydride, Sorption, Water vapour, Decay resistance, Coniophora puteana, Scots pine.

Contact information: Technological Educational Institute of Kavala, Branch of Drama, Department of Forestry and Management of Natural Environment, Drama, TK 66100, Greece. Email: antonios1974@hotmail.com,antpap@teikav.edu.gr

\section{INTRODUCTION}

Two goals of chemical modification of wood are to improve dimensional stability and decay resistance. Various chemical modification reactions have been studied for these purposes (Rowell, 1983). Acetylation is the most studied area of wood modification. For example, Stamm and Tarkow (1947) measured the equilibrium moisture content (e.m.c) of unreacted and vapour phase acetylated (30\% acetyl content) Sitka spruce at various humidities and found a $67 \%$ reduction in water sorbed at $95 \%$ relative humidity. It has been shown that the dimensional stability of wood can be effectively improved by esterification with anhydrides (Rowell et al. 1988). There is limited work reported on the water vapour sorptive properties of such modified woods. A number of authors have investigated the sorption isotherms of acetylated wood specimens at only one level of substitution (Risi and Arseneau 1957; Spalt 1958; Popper and Bariska 1972; Yasuda et al. 1995). Although the effect on overall stabilisation in response to liquid water soaking is well documented (Stamm 1964; Rowell 1983; Hill and Jones 1996), there is little evidence of how sorption is influenced by esterification with anhydrides. Peterson and Thomas (1978) acetylated loblolly pine, green ash and yellow poplar using acetic anhydride in xylene. The modified samples were tested against the brown rot fungus $G$. trabeum and the white rot fungus Coriolus versicolor. It was found that the white rot was generally easier to control than the brown rot, with levels of acetylation as low as $7 \%$ being able to provide protection against rot.

Although of all the methods investigated, modification using acetic anhydride has received by far the most attention, there have been a number of papers published 
concerning modification of wood with other linear chain anhydrides (Rugevista and Embrehsha 1988; Hill and Jones 1996; Hill and Papadopoulos 2002). Stamm and Tarkow (1947) reported that they propionylated and butyrylated whole wood and veneer, using pyridine as a catalyst, in the vapour or liquid phase using the corresponding anhydrides. It was reported that modified samples showed no sign of decay after three months exposure to Poria versicolor, whereas the unmodified samples showed weight losses of up to 50\%. Suttie et al. (1999), modified Scots pine with acetic, propionic, butyric, or hexanoic anhydrides and determined decay resistance against the brown rot fungi Coniophora puteana, Gloeophyllum trabeum, Poria placenta and a white rot fungus (Coriolus versicolor) using European Standard method EN113 and a vermiculite overlay method. Resistance to soft rot attack was also determined using a modified ENV 807 stake test in unsterile soil. The effect of different levels of reaction upon decay resistance was only tested with the soft rot experiment. In this, it was found that a threshold of $c a .23 \%$ was required to ensure protection, regardless of the anhydride used.

The purpose of this paper is to show the effects of level of substitution on dimensional stability and decay resistance of a linear chain anhydride (propionic anhydride) modified Scots pine sapwood. The choice of propionic anhydride was based on (i) the limited information that exists in the literature, especially as far as the decay resistance of propionylated wood is concerned and (ii) its lower cost compared to other linear chain anhydrides (i.e. butyric, valeric, hexanoic). The reaction between wood and propionic anhydride is a single site reaction as depicted in Figure 1 and yields the corresponding carboxylic acid (propionic acid) as a by-product of its reaction with wood.

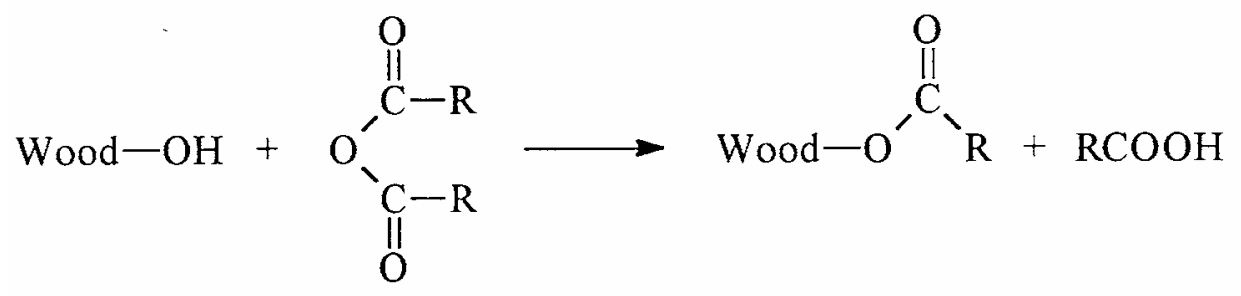

Fig. 1. Reaction of wood with propionic anhydride $\left(\mathrm{R}=\mathrm{C}_{2} \mathrm{H}_{5}\right.$ propionic anhydride).

\section{EXPERIMENTAL}

\section{Chemical Modification of Wood Samples}

Scots pine (Pinus sylvestris) sapwood samples of dimension $20 \mathrm{~mm}$ x $20 \mathrm{~mm}$ x 5 $\mathrm{mm}$ (radial $\mathrm{x}$ tangential $\mathrm{x}$ longitudinal) were cut from freshly felled kiln dried logs. Samples were carefully sanded to remove loosely adhering fibres, then placed in a Soxhlet extractor for solvent extraction using toluene/methanol/acetone $(4: 1: 1$ by volume) for eight hours. Samples were dried in an oven for eight hours at $105^{\circ} \mathrm{C}$. Prior to weighing (four figure balance), samples were transferred to a vacuum desiccator and allowed to cool to ambient temperature over silica gel. Weighed samples $\left(\mathrm{W}_{1}\right)$, were vacuum impregnated with pyridine for one hour then transferred to a flask containing pyridine set in an oil bath at $100^{\circ} \mathrm{C}$. Pyridine swells the wood and acts as a catalyst for the modification reaction. Samples were allowed to equilibrate in the hot pyridine for 
one hour. Sets of hot samples (twenty-eight replicates) were added to a flask containing a one molar solution of the propionic anhydride in pyridine set in an oil bath at $100^{\circ} \mathrm{C}$ for a specific length of time to achieve the desired level of modification. At the end of the reaction period, the flask was removed from the oil bath, the hot reagent decanted off and ice cold acetone added to quench the reaction. Samples were allowed to sit in the acetone for one hour before being transferred to the Soxhlet apparatus for solvent extraction as detailed previously. Samples were re-weighed $\left(\mathrm{W}_{2}\right)$ after oven drying as detailed previously. Samples were free of reagent, by-product and pyridine after this procedure.

The extent of reaction was calculated as weight percent gain (WPG) determined by the differences in oven dry weight of the sample before modification $\left(\mathrm{W}_{1}\right)$ and after modification $\left(\mathrm{W}_{2}\right)$ according to the equation [Weight percent gain $(\mathrm{WPG})=\left(\mathrm{W}_{2}-\mathrm{W}_{1}\right)$ / $\left.\mathrm{W}_{1} \times 100\right]$.

\section{Infra-red (IR) Analysis}

For Infra-red (IR) analysis, the treated samples were ground up by using a microdismembrator $(20.000 \mathrm{rpm}$ for $6 \mathrm{~min}$ ). The fibre flour was then mixed with ovendry potassium bromide $(\mathrm{KBr})$ powder (the fibre flour $/ \mathrm{KBr}$ ratio was $1: 100$ ) and placed in a vibratory ball mill capsule. The mixture was ground for about $2 \mathrm{~min}$. The ground mixture was then transferred to a press and the bolts of press screwed down. The bolts were tightened with a spanner to press the disk. After a few minutes, the bolts were loosen and removed. The press was placed directly into a sample beam of a Mattson FTIR spectrometer, Nicolet 750, series II.

\section{Decay Tests}

The samples were packed in an argon atmosphere and sterilised by irradiation $(2.5$ $\mathrm{mrad})$ prior to decay tests. Each set of 16 modified and unmodified control samples at each level of treatment was subdivided into four groups of four replicates. Laboratory pure strains of the brown rot fungi Coniophora puteana (No FPRL 11E) were used, grown on malt agar. Four unmodified control or modified wood samples were planted on sterile specimen supports placed on the cultures of the test fungus actively growing on $5 \%$ malt agar in $500 \mathrm{ml}$ capacity jars (EN 113, 1996; the only modification was the sample size, see 2.1). An additional set of sterile control samples were used to assess operational control losses. The closed jars were incubated for 16 weeks, at $22+/-1^{0} \mathrm{C}$ and $75+/-5 \%$ relative humidity to evaluate the efficacy of the treatments. After incubation, the samples were removed from the jars, cleaned, dried overnight at $105^{\circ} \mathrm{C}$ and weighed. Weight loss was expressed as a percentage of the initial oven dried weight of the sample. Weight losses from sterile controls were subtracted from the decay results to give corrected data.

\section{Equilibrium Moisture Content}

The method for controlling relative humidity, as described by Stamm (1964), has been widely used and was selected for being simple, economical and reasonably precise. Test samples were kept above saturated solutions of various salts in containers stored in a controlled temperature room set at $20^{\circ} \mathrm{C}$ (variation $+/-1^{\circ} \mathrm{C}$ ). Pure water results in the saturated vapour pressure corresponding to $100 \%$ relative humidity. The addition of a 
solute to water reduces its vapour pressure in proportion to its mole fraction in the case of diluted solutions. When a saturated solution at a controlled temperature is used, a constant relative humidity is maintained (Siau 1996).

Six salts were chosen and these are listed in Table 1, along with the relative humidity of the atmosphere above each saturated solution at $20^{\circ} \mathrm{C}$ (according to Kaye and Laby 1966). They were chosen on the basis of giving minimum relative humidity variation with changes in the temperature (Stamm 1964). Excess salt was always present within each solution to ensure saturation was maintained. The solution and air in the container were agitated by bubbling air through the solution.

Table 1. Saturated salt solutions used and their resultant relative humidities at $20{ }^{\circ} \mathrm{C}$.

\begin{tabular}{|l|c|}
\hline \multicolumn{1}{|c|}{ Salt } & Relative humidity (\%) \\
\hline Potassium nitrate $\left(\mathrm{KNO}_{3}\right)$ & 93 \\
\hline Sodium chloride $(\mathrm{NaCl})$ & 76 \\
\hline Sodium dichromate $\left(\mathrm{Na}_{2} \mathrm{Cr}_{2} \mathrm{O}_{7}\right)$ & 55 \\
\hline Potassium carbonate $\left(\mathrm{K}_{2} \mathrm{CO}_{3}\right)$ & 44 \\
\hline Potassium acetate $\left(\mathrm{CH}_{3} \mathrm{COOK}\right)$ & 23 \\
\hline Lithium chloride $(\mathrm{LiCl})$ & 12 \\
\hline
\end{tabular}

The oven dry wood samples (two replicates) were placed in the containers above saturated salt solutions. They were left to equilibrate for 4 weeks and then weighed once a week, using a four-place analytical balance until it became obvious that no significant weight change had occurred since the last weight was recorded (and e.m.c had been attained). Equilibrium moisture content (e.m.c) was reached within 6 weeks for all but the two highest humidities, which required longer exposure times.

\section{RESULTS AND DISCUSSION}

\section{Infra-red (IR) Analysis}

Scots pine samples were satisfactorily reacted with propionic anhydride at $100^{\circ} \mathrm{C}$ under the pyridine catalysis. The esterification of wood was established by infra-red spectroscopy (Figure 2). The infra-red spectra confirmed the occurrence of woodanhydride reaction. The strong vibration obtained in the region of 1736 and $1730 \mathrm{~cm}^{-1}$ $(\mathrm{C}=\mathrm{O})$ was a distinct pattern present in modified samples, which indicates ester bond formation. As expected, such absorption was not present in unmodified wood.

\section{Decay Resistance of Modified Wood}

The chemical modification of wood with propionic anhydride afforded substantial bioprotection of Scots pine against Coniophora puteana (Table 2). The data (weight loss $v s$ weight percent gain) were plotted and the fit (dash line in Figure 3) shown by linear 


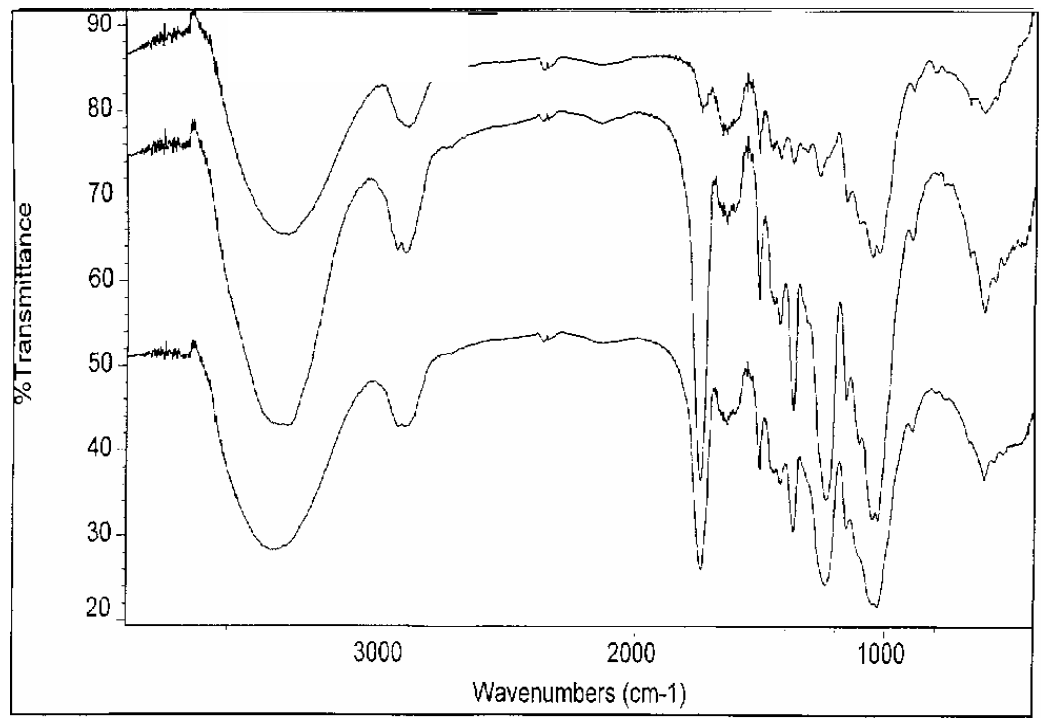

Fig. 2. FTIR spectra of unmodified control (top), propionic anhydride modified at $25.4 \%$ WPG (middle), and propionic anhydride modified at 5.6\% WPG (bottom).

regression analysis indicates a positive relationship between extent of modification and decay resistance $\left(\mathrm{R}^{2}=0.88\right)$. Next, the sterile control data were plotted against the weight percent gain data to give a linear fit (dot line in Figure 3). The point that one line crosses the other determines the threshold value (Figure 3). The threshold value of protection of propionic anhydride was $17 \%$; it is suggested therefore that a WPG of approximately $17 \%$ is required following reaction to ensure complete protection. Earlier soil block decay tests by Goldstein et al. (1961) and Peterson and Thomas (1978) showed adequate decay resistance against brown rot fungi in wood treated with acetic anhydride to $17 \%$, whereas Forster (1998) reported a higher value (24\%). Soft rot soil bed tests by Suttie et al. (1998) showed that a value of approximately $23 \%$ is required to ensure complete protection of wood treated with the series of anhydrides used in the present study against Coniophora puteana.

Table 2. Weight percent gain (WPG) and weight losses of Scots pine sapwood modified with propionic anhydride. (Standard deviation in parentheses).

\begin{tabular}{|c|c|c|c|c|c|}
\hline Treatment & $\begin{array}{c}\text { Reaction Time } \\
(\mathrm{min})\end{array}$ & $\begin{array}{c}\text { WPG } \\
(\%)\end{array}$ & \multicolumn{3}{|c|}{ Weight Loss (\%) } \\
\hline & & & C. puteana & Sterile controls & Corrected \\
\hline Control & 0 & 0 & $64.64(2.5)$ & $0.29(0.1)$ & 64.35 \\
\hline Propionic & 45 & $5.6(0.3)$ & $41.14(8.3)$ & $0.6(0.3)$ & 41.08 \\
\hline & 105 & $14.8(0.2)$ & $4.10(2.3)$ & $0.45(0.2)$ & 3.65 \\
\hline & 300 & $20.5(0.7)$ & $1.89(0.4)$ & $0.37(0.3)$ & 1.52 \\
\hline & 420 & $25.4(0.4)$ & $1.60(0.3)$ & $0.54(0.2)$ & 1.06 \\
\hline
\end{tabular}




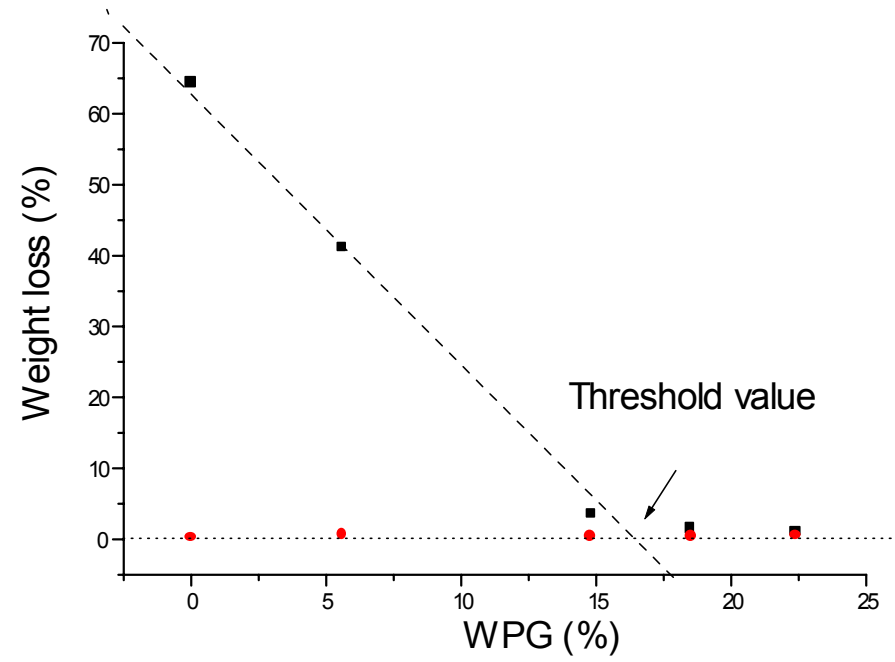

Fig. 3. Determination of threshold value of protection.

\section{Sorption of Water Vapour of Modified Wood}

The e.m.c's at various levels of relative humidity for Scots pine sapwood modified with propionic anhydride are presented in Table 3. Table 3 indicates an obvious trend of reducing water vapour sorption with increasing WPG, which is true for the whole range of relative humidity. This is in agreement with the results reported earlier on various lignocellulosic fibres modified with acetic anhydride (Rowell and Rowell1989).

Table 3. Mean values for experimentally derived equilibrium moisture contents (e.m.c's) at various levels of relative humidity for Scots pine sapwood modified with propionic anhydride. (Standard deviation in parentheses).

\begin{tabular}{|c|c|c|c|c|c|c|c|}
\hline Reagent & WPG(\%) & & & EMC (\%) & & & \\
\hline & & 12 & 23 & 44 & 55 & 76 & 93 \\
\hline Control & 0 & $2.33(.05)$ & $4.19(.09)$ & $7.02(.02)$ & $8.38(.09)$ & $12.68(.19)$ & $18.95(.28)$ \\
\hline Propionic & 6.1 & $2.01(.08)$ & $3.45(.08)$ & $5.62(.14)$ & $6.88(.05)$ & $10.45(.05)$ & $15.62(.24)$ \\
\hline & 10.9 & $1.81(.08)$ & $2.71(.09)$ & $5.19(.05)$ & $6.15(.14)$ & $9.33(.14)$ & $13.86(.15)$ \\
\hline & 15.6 & $1.33(.05)$ & $2.1(.12)$ & $4.05(.14)$ & $5.01(.15)$ & $7.62(.12)$ & $12.01(.18)$ \\
\hline & 19.7 & $1.19(.09)$ & $2.11(.05)$ & $3.32(.09)$ & $4.01(.11)$ & $6.55(.08)$ & $9.98(.15)$ \\
\hline & 24.5 & $0.9(.12)$ & $1.62(.05)$ & $2.77(.15)$ & $3.65(.05)$ & $5.71(.08)$ & $9.42(.12)$ \\
\hline
\end{tabular}

\section{CONCLUSIONS}

1. A catalysed reaction between Scots pine sapwood and propionic anhydride was established by increase in weight and by infra-red spectra.

2. Chemically modified Scots pine sapwood with propionic anhydride afforded substantial bioprotection against Coniophora puteana. 
3. It required a weight gain of approximately $17 \%$ following reaction to ensure complete protection against Coniophora puteana.

4. The sorption of water vapour of propionic anhydride modified wood was greatly reduced.

\section{REFERENCES CITED}

EN 113 Wood Preservatives (1996). Determination of the toxic values against wood destroying Basidiomycetes cultured on an agar medium, British Standards Institution. EN 113 (1982), BS 6009 (1982), 15.

Forster, S. (1998). Decay resistance of modified softwood, Ph.D thesis, University of Wales, Bangor.

Goldstein, I. S., Jeroski, E. B., Lund, A. E., Nielson, J. F., and Weaver, J. W. (1961). "Acetylation of wood in lumber thickness," Forest Products Journal 11(8), 363-370.

Hill, C. A. S., and Jones, D. (1996). "The dimensional stabilisation of Corsican pine sapwood by reaction with carboxylic acid anhydrides," Holzforschung 50, 457-462.

Hill, C. A. S., and Papadopoulos, A. N. (2002). "The pyridine-catalysed acylation of pine sapwood and phenolic model compounds with carboxylic acid anhydrides.

Determination of activation energies and entropy of activation," Holzforschung 56, 150-156.

Kaye, G. W. C., and Laby, T. H. (1966). Tables of physical and chemicals constants and some mathematical functions, Longmans.

Peterson, M. D., and Thomas, R. J. (1978). "Protection of wood from decay fungi by acetylation. An ultrastructural study,"Wood and Fiber 10(3), 149-163.

Popper, R., and Bariska M. (1972). "Acylation of wood. Part I: The sorption behaviour of water vapour," Holz Roh Werkstoff 30, 289-294.

Risi, J., and Arseneau D. F. (1957). "Dimensional stabilisation of wood. Part I: Acetylation," Forest Products Journal 7, 210-213.

Rowell, R. M. (1983). "Chemical modification of wood," Forest Products Abstracts 6(12), 366-382.

Rowell, R. M., and Rowell, J. S. (1989). Moisture sorption properties of acetylated lignocellulosic fibres. In: Proceedings of the $10^{\text {th }}$ cellulose conference, C. Schuerch, ed., John Wiley and Sons, New York, 343-355.

Rowell, R. M., Youngquist, J.A., and Montrey, H.M.. (1988). "Chemical modification: adding value through new FPL composite technology," Forest Products Journal 38, 67-70.

Rugevista, A. A., and Embrehsha, A. E. (1988). "Modification of wood with acylating agents and polyethylene glycol," Trudy-Latviiskoi-Sel'skokhozyaistevennoi-Akad. 253 39-44.

Siau, J. F. (1996). Wood: influence of moisture on physical properties, Department of Wood Science and Forest Products, Virginia Polytechnic Institute and State University.

Spalt, H. A. (1958). "The fundamentals of water vapour sorption by wood," Forest Products Journal 8, 288-295. 
Stamm, A. J. (1964). Wood and Cellulose Science, The Ronald Press, New York.

Stamm, A. J., and Tarkow, H. (1947). "Dimensional stabilisation of wood," Journal of Colloid Chemistry 51, 493-505.

Suttie, E. D., Hill, C. A. S, Jones, D., and Orsler R. J. (1999). "Chemically modified solid wood. I. Resistance to fungal attack,"Material und Organismen 32, 159-182.

Yasuda, R., Minato, K., and Norimoto, M. (1995). "Moisture adsorption thermodynamics of chemically modified wood," Holzforshung 49:548-554.

Article submitted: May 16, 2006; Revision accepted: July 14, 2006; Published July 15, 2006 